\title{
PROJETO DE INTERVENÇÃO ARQUEOLÓGICA EM PORTO SEGURO
}

A cidade de Porto Seguro vem experimentando, nos últimos anos, um processo de transformação substancial decorrente do fenômeno de turismo de massa.

A indústria turística, iniciada por particulares, e que hoje conta com incentivo da administração estadual, provocou, em um breve período de tempo, alterações na ordem econômica, conseqüentemente notável aumento da população fixa, recepção massiva de contingentes temporários, expulsão da população originária para bairros satélites, extensão da área residencial da cidade e reformulação funcional de diversos setores.
As alterações de características urbanísticas, derivadas deste acelerado processo de mudanças, afetaram notavelmente a paisagem urbana e natural $\mathrm{e}$ colocaram em risco o patrimônio arquitetônico e arqueológico da cidade. Do ponto de vista da estrutura de saneamento, a rede de serviços básicos tornou-se insuficiente, posto que não acompanhou o crescimento desmesurado do contingente populacional.

Por estas circunstâncias, está sendo levado a cabo um programa de obras sanitárias, por parte da EMBASA - Empresa Baiana de Águas e Saneamento, que implicou na abertura de $22 \mathrm{~km}$ de trinchęiras para o assentamento da rede de encanamento em todos os setores da cidade. ${ }^{1}$

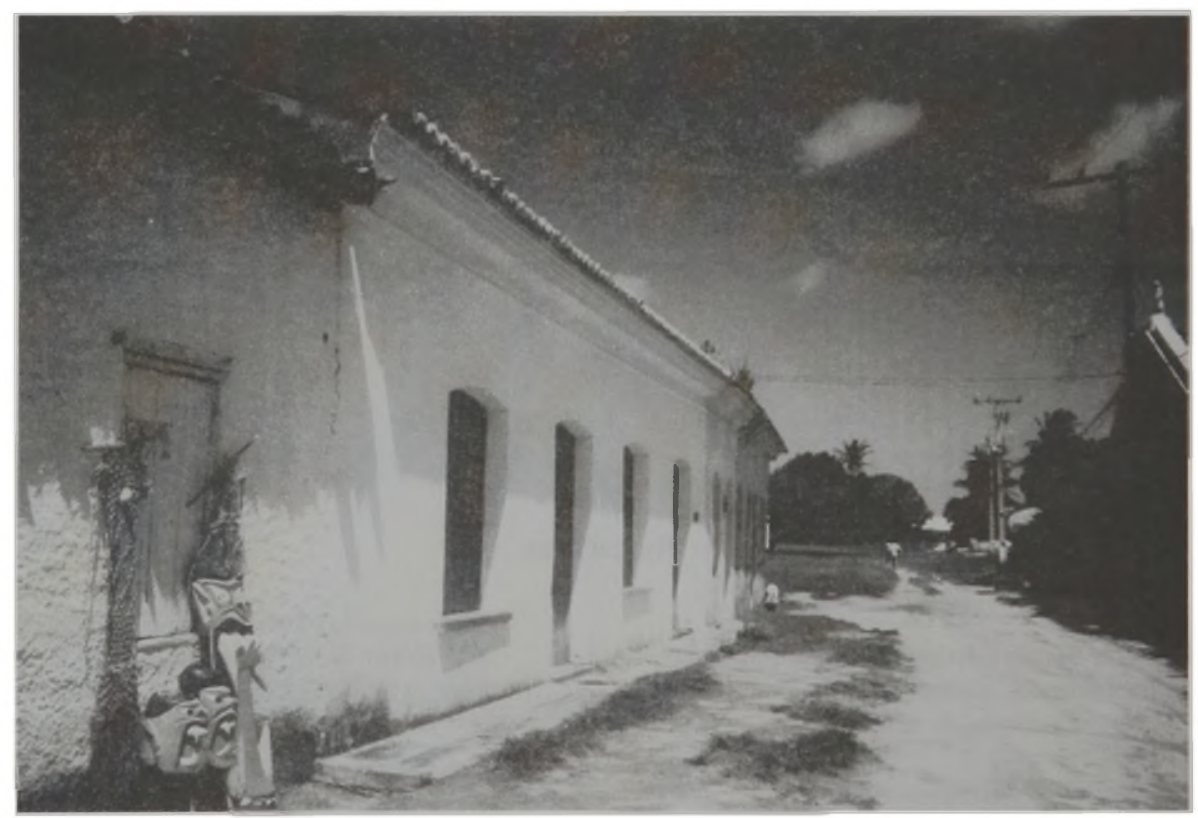

Foto 1 - Vista parcial do Centro Histórico da Cidade Alta.

(1) Estas obras, iniciadas em agosto de 1996, contam com o gerenciamento direto da EMBASA (Empresa Baiana de águas e saneamento), execução a cargo da Construtora OAS Ltda., financiadas através do Programa para o Desenvolvimento do Nordeste PRODETUR, contando ainda com recursos do BID (Banco Interamericano de Desenvolvimento), do BNB (Banco do Nordeste do Brasil) e do Governo do Estado da Bahia. 


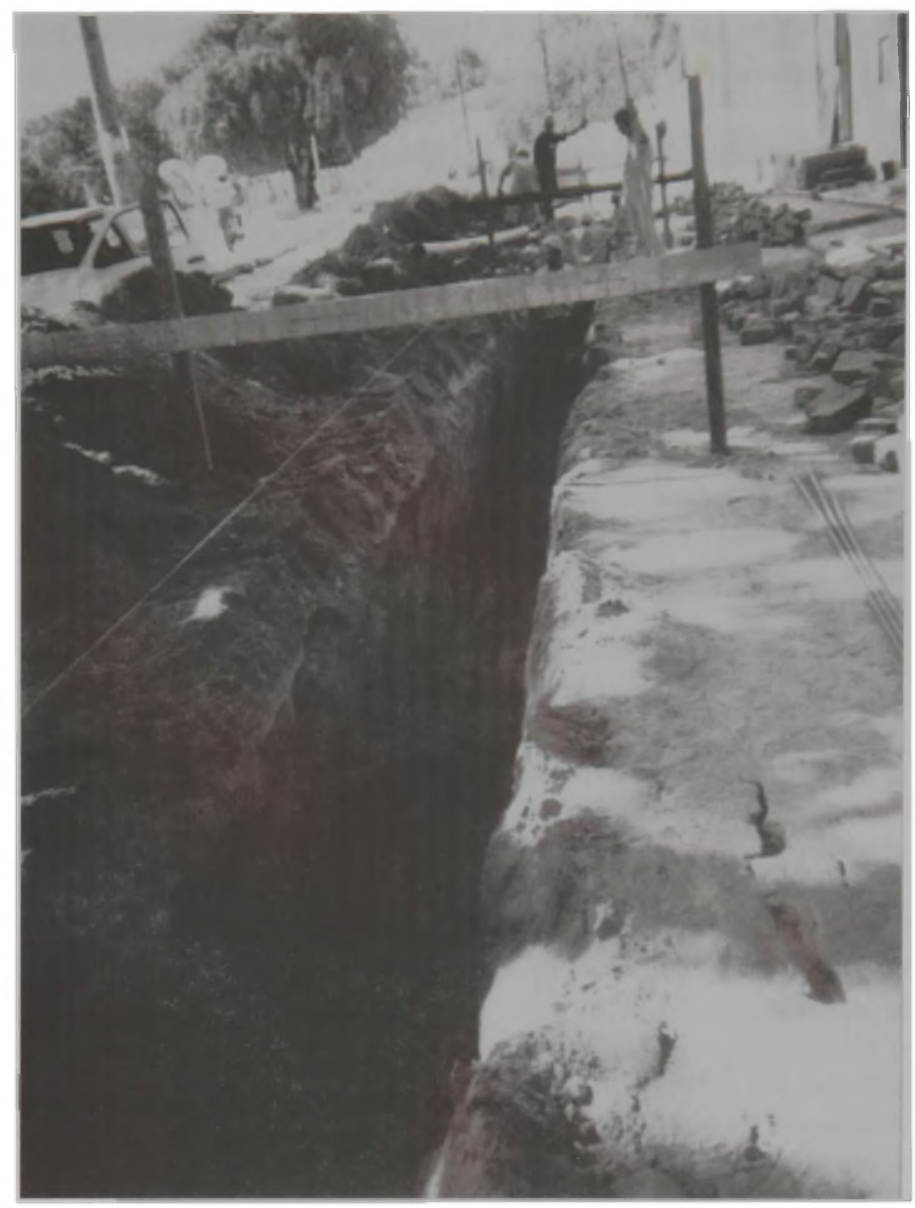

Foto 2 - Abertura de trincheiras e assentamentos da rede de água.

Por exigências legais, o IPHAN - Instituto do Patrimônio Histórico e Artístico Nacional - exigiu que especialistas deveriam intervir neste programa. Desta maneira, foi convocado o Museu de Arqueologia e Etnologia da Universidade Federal da Bahia (MAE/UFBA) para elaborar um plano de ação arqueológica. Cabe ressaltar que a UFBA tem realizado, em diferentes momentos, trabalhos de pesquisa de característica etnológica, etno-histórica e arqueológica no município de Porto Seguro.

Neste contexto, foi possível conciliar o trabalho emergencial das obras de saneamento básico, com uma proposta de intervenção arqueológica que permitisse ao mesmo tempo controlar os trabalhos de engenharia e redundasse em benefício do conhecimento do acervo do patrimônio ar- queológico desta cidade. A instalação da rede de ampliação do sistema de abastecimento de água e instalação do sistema de esgotamento sanitário desta cidade permitiram conhecer o subsolo do núcleo urbano oferecendo uma longa rede de perfis estratigráficos (Foto 1). A proposta de pesquisa que acompanhou o plano de intervenção tem por objetivo confrontar os dados oferecidos pela abertura de trincheiras, identificando áreas de refugos e estruturas subjacentes, com o levantamento de estruturas emergentes em ruínas dos setores monumentais e com os aspectos tipológicos ainda reconhecidos nas residências e nas ruas do tecido urbano atual (Foto 2).

A isto, juntar-se-ão informações de fontes documentais escritas do Arquivo Histórico Estadual 
da Bahia, da Biblioteca Nacional e da Cúria e Arquivo Municipal do Município de Teixeira de Freitas. $^{2}$

Acreditamos que este conjunto de dados possa permitir a construção do processo de ocupação neste núcleo urbano, revelando assim a diacronia na dinâmica de uso e abandono de espaços, a qualificação funcional desta utilização: setores que foram preferenciais para funções especiais (residências, administração pública e atividades econômicas) e as relações do espaço com o status social.

No decorrer dos trabalhos, apresentou-se uma nova perspectiva de análise, que se trata do uso de certo tipo de material arqueológico para comprovar relações inter-regionais. Refere-se à vinculação

Recebido para publicação em 18 de julho de 1997. econômica entre o núcleo urbano de Porto Seguro com Salvador e Recôncavo Baiano, no período colonial e independente. De fato, alguns elementos aludem a uma possível dependência de Porto Seguro, no que respeita ao material construtivo, telhas e tijolos, e também vasilhames domésticos, especialmente cerâmica vidrada. Esta tipologia deverá ser considerada com exames aprofundados do material arqueológico, com comparações com estes correspondentes em Salvador e no Recôncavo e ainda com fontes documentais escritas.

Carlos Etchevarne* Leticia de Barros Motta**
(2) Município próximo a Porto Seguro, onde se concentram todo os livros paroquiais do extremo sul da Bahia.
(*) Museu de Arqueologia e Etnologia, Departamento de Antropologia da Universidade Federal da Bahia.

(**) Museu de Arqueologia e Etnologia da Universidade de São Paulo. Pós-Graduação, mestrado. 